\title{
Realidades, Construcciones y Dilemas. Una revisión filosófica al construccionismo social
}

\author{
Realities, Constructions and Dilemmas. A philosophical revision to the social \\ CONSTRUCTIONISM
}

Mg. Pablo López-Silva (pablo.lopez.silva@gmail.com) Department of Philosophy, The University of Manchester (Manchester, United Kingdom)

\begin{abstract}
The following paper presents and discuses the epistemological premises of one of the relativistic expressions of the so-called constructivism i.e. the social constructionism. Firstly, we trace constructivism's theoretical origins and later, we distinguish the main ideas of Kenneth Gergen's social constructionist proposal. The analysis is done in the following way: (a) we analyse the epistemological premises and the philosophical problems arising from them, and (b) we analyse the problematic impact these premises have in the praxis of social sciences. Finally, we conclude that the exclusion of clear philosophical distinctions inside social constructionism undermines social constructionism's plausibility.
\end{abstract}

Key words: constructivism, social constructionism, Gergen, praxis, postmodernism.

\section{Resumen}

El siguiente artículo presenta y discute los postulados epistemológicos de una de las expresiones relativistas del denominado constructivismo i.e. el construccionismo social. En primer momento, se rastrean los orígenes teóricos del constructivismo y, posteriormente, se distinguen los principales postulados del construccionismo social de Kenneth Gergen. El análisis se realiza del siguiente modo: (a) Se analizan los supuestos epistemológicos y los problemas filosóficos derivados de éstos, y (b) Se analizan las consecuencias que los postulados construccionistas tienen en la praxis que llevan a cabo las ciencias sociales. Finalmente, se concluye que la exclusión de distinciones filosóficas claras por parte del construccionismo social le resta plausibilidad al enfoque.

Palabras clave: constructivismo, construccionismo social, Gergen, praxis, posmodernidad.

\section{Introducción}

La así llamada "posmodernidad" ha propuesto importantes cambios en los cimientos filosóficos de las ciencias sociales. En los últimos veinte años, ciertos postulados posmodernos se han instalado en diversas áreas aplicadas, tales como la sociología, la antropología, la educación y de forma importante en la psicología (1). A pesar de esta clara influencia de todo aquello que llamamos 'posmodernidad', el término es bastante difícil de definir. Con todo, podemos indicar que este término en ningún caso hace referencia a un corpus de pensamiento uniforme; más bien, el concepto parece ser mejor definido como una actitud ante la realidad; una actitud que pretende refinar nuestra sensibilidad a la multiplicidad de caminos y verdades, incrementando -postulan los posmodernos- nuestra 
tolerancia hacia elementos que a fin de cuentas serían inconmensurables (2). De esta forma, la posmodernidad se levanta como un espacio de crítica al status del conocimiento y de los también así llamados "grandes relatos" que gobernaron el conocimiento hasta el siglo XX. Con el fin de delimitar el concepto, Eagleton distingue entre los términos "posmodernidad" y "posmodernismo" (3). El primero, se define como un período histórico en donde se critican las nociones de verdad, objetividad y razón. Esta definición es complementaria a la ofrecida por Owens, ya que este período histórico se caracterizaría por una actitud crítica hacia la verdad, la objetividad, y la razón. Por otra parte, el término "posmodernismo" también parece emplearse para caracterizar la cultura contemporánea. Con todo, ambos términos, "posmodernidad" y "posmodernismo" parecen en general emplearse indistintamente. Pues bien, sea como fuere, el caso es que las propuestas constructivistas parecen haber hallado su sustento epistemológico y práctico en este marco así llamado "posmoderno". Sin embargo, y este es el problema que abordaremos, creemos que los postulados constructivistas no ha incluido una apropiada reflexión filosófica, ni acerca de sus premisas epistemológicas, ni acerca de sus consecuencias prácticas.

El siguiente trabajo (4) propone un breve análisis filosófico a una de las dimensiones relativistas del movimiento constructivista, es decir, el construccionismo social de Kenneth Gergen (1985, 1996, entre otros). Tras revisar las principales premisas epistemológicas del construccionismo, se argumenta que pese a las advertencias de Gergen, el construccionismo social deviene antirrealista, relativista y reduccionista; lo que trae nefastas consecuencias para la praxis de las ciencias sociales.

El análisis pondrá su atención en dos focos: (a) la plausibilidad de los postulados epistemológicos del construccionismo social y; (b) las consecuencias que estos postulados construccionistas tienen para la praxis de las ciencias sociales.

\section{Desde el constructivismo al construccionismo social. El continuo constructivista}

Antes de analizar la propuesta socioconstruccionista, podemos responder algunas preguntas que nos ayudarán a comprender el origen y marco teórico. ¿Qué es, pues, el constructivismo y cuál es su relación con el socioconstruccionismo?

Parece existir un acuerdo que indica que no hay un único tipo de constructivismo. Por ejemplo, Matthews afirma que el término "constructivismo" toma un significado diferente dependiendo del investigador. Es más, parece no tener sentido hablar acerca de un "corpus teórico constructivista" uniforme, robusto y bien definido. Es por esto que diversos autores prefieren referirse, más bien, al constructivismo como "orientaciones constructivistas" (5).

Con todo, a pesar de que el término puede parecer confuso, es posible rastrear algunos elementos rudimentarios del origen en el trabajo de Giambattista Vico, George Kelly y Von Glaserfeld. Estos autores -entre otros- definen la naturaleza de la realidad como una "construcción", es decir, como producto de la acción humana.

Una de las influencias filosóficas más importantes del constructivismo se encuentra en el trabajo de Kant. El filósofo alemán dividió el objeto de nuestro conocimiento en noúmeno y fenómeno, sugiriendo que no podemos conocer la verdadera y última naturaleza del fenómeno, sino que solo su manifestación en nuestra conciencia. Tal manifestación estará determinada por las categorías trascendentales del sujeto trascendental. En consecuencia, Kant propone que nuestra realidad es en cierto sentido una construcción mental determinada por las categorías mentales previas a la experiencia con las cuáles contamos. Sin embargo, es importarte indicar que esto constituye solo un antecedente indirecto de los orientaciones constructivistas, y no el desarrollo temprano de ellas. Si bien Kant propone un importante aporte en torno a la naturaleza constructiva de la mente humana, nunca indicó que 
aquello que es construido no posea realidad objetiva; es decir, que no se construya sobre algo. Kant solamente restringió las posibilidades de acceso al objeto, indicando que si bien existe noúmeno, sólo lo conocemos en el 'fenómeno'. Luego, nuestras categorías mentales participarían activamente tomando parte en la construcción de tal manifestación.

Sobre esto, Boghossian indica lo siguiente: "According to Kant, for example, the world we experience is constructed by our minds to obey certain fundamental laws, among them the laws of geometry and arithmetic. But Kant didn't think we were free to do otherwise. On the contrary, he thought that any conscious mind was constrained to construct a world which obeys those laws" (2006:18).

A pesar de esta última distinción, la relación influencia de Kant en los postulados constructivistas parecen ser claramente reconocible.

A pesar de la falta de claridad que ha sido asociada a la definición de lo que es el constructivismo, podemos distinguir algunas ideas básicas que comparten las casi 200 expresiones constructivistas documentadas por Feixas y Villegas (2000).

En la noción más básica del constructivismo, el autoconocimiento y el conocimiento de la realidad emergen como un producto de la interrelación entre las acciones humanas y el ambiente (Feixas y Villegas). Por lo tanto, se niega la idea de una realidad aprehendida de forma pasiva y completamente objetiva (Mahoney). Toda realidad es una expresión de la misma estructura de quien conoce, y por lo tanto, el sujeto participa activamente en el proceso de construcción de tal realidad (Maturana). Von Foerster declarará a su vez que nuestra realidad tal cual como la percibimos en una invención nuestra.

El constructivismo parece reproducir en sus premisas epistemológicas la crítica estándar del posmodernismo al status objetivo del conocimiento. Saunders indica que la realidad es una construcción realizada por aquel que la describe. Para Glasersfeld el conocimiento de la realidad no puede ser objetivo debido a que el término "conocimiento" denota un tipo de relación entre los seres humanos y su mundo, relación que estará siempre determinada por la estructura humana. Sobre esto Von Foerster indica que el conocimiento de la realidad no es independiente de la estructura humana. La expresión "estructura humana" puede tener diversas explicaciones en el constructivismo. Es más, las diversas expresiones constructivistas parecen separarse unas de otras dependiendo de la forma en que definen esto. Por ejemplo, Maturana/Varela y Von Foerster refieren a la estructura biológica humana como aquel elemento crucial que determina el conocimiento de la realidad. Gergen indica que la estructura social humana es el elemento crucial en la determinación del conocimiento de la realidad.

En el constructivismo, el conocimiento ya no pretende ser entendido como un conocimiento objetivo. Tal pretensión de objetividad es reemplazada por el concepto de viabilidad. Esta viabilidad -una vez más- puede ser entendida en diversas formas. Guidano entenderá la viabilidad del conocimiento como una viabilidad "psicológica", Maturana y Varela, por su parte, la entenderá como "viabilidad adaptativa" y Gergen la entenderá como "funcionalidad social".

Otra de las pretensiones más importantes de las orientaciones constructivistas es consumar una crítica sistemática al dualismo cartesiano en tanto relación sujeto-objeto. Gergen indicará que la superación de la tradición dualista propuesta por la posmodernidad, sugiere el reemplazo de un sujeto pasivo y receptor de la realidad, por uno activo en la construcción de ésta. 
Es importante hacer notar que dentro del multiforme escenario constructivista, la naturaleza constructiva de la mente humana transita por un continuo que va desde el subjetivismo absoluto hasta el relativismo social absoluto. Tales posiciones logran incluso distinguirse como dos polos dentro de lo que he denominado el "continuo constructivista". Con todo, podemos distinguir algunas fases básicas en este continuo (6). Tales fases nos ayudarán a comprender de mejor manera el lugar que toma el construccionismo social en relación con el constructivismo.

Básicamente, este polo entiende las capacidades cognitivas individuales como el principal elemento en el proceso de construcción del conocimiento. En una paráfrasis a Protágoras, Von Glasersfeld sugiere que la mente humana es la medida de todas las cosas. A tal posición se le ha denominado "constructivismo radical" (una de las obras más sobresalientes de esta expresión constructivista es La Realidad Inventada de Watzlavik). Por otra parte, el denominado "constructivismo clásico" propone que la mente humana construye la realidad, pero dentro de una relación sistemática con el medio ambiente (Piaget, Kelly). Esta expresión constructivista propondría una forma atenuada de constructivismo subjetivista.

Por otra parte, el "constructivismo social", que encuentra sus principales fuentes en los trabajos de Vygotsky y Bruner, entre otros, también indica que la mente construye la realidad a través de su relación con el mundo. Sin embargo, este proceso mental de construcción está determinado por la influencia de las relaciones sociales que el sujeto posee cuando lleva acabo la acción constructiva. En este punto, ya podemos observar que los planteamientos constructivistas gradualmente pasan desde un foco subjetivista a uno relativista.

En el polo relativista, el "construccionismo sociológico" indica que las formas que toma el conocimiento de la realidad y del yo están determinadas por la influencia que ejercen las estructuras sociales e ideológicas sobre las formas de pensar de los sujetos. Finalmente, el "construccionismo social" de Kenneth Gergen se posiciona como la expresión más radical de las expresiones relativistas del constructivismo, dado que indica que el conocimiento es simplemente una "construcción social", que es reproducida por medio de operaciones lingüísticas cotidianas en el seno de discursos previos al sujeto. Es importante hacer notar que las expresiones constructivistas de esta naturaleza reproducen claramente la crítica posmoderna a la modernidad. Por ejemplo, Kenneth Gergen cita el trabajo de Michel Foucault, Richard Rorty y Jacques Derrida, entre varios otros, como algunas de sus principales fuentes.

\section{El construccionismo social}

\subsection{El proyecto construccionista y sus influencias}

Existen diversas expresiones posibles de ser denominadas como "construccionismo social". Sin embargo, todas ellas pueden ser fácilmente localizadas dentro del polo relativista del continuo constructivista. Dentro de éstas, la propuesta de Kenneth Gergen se ha posicionado como uno de los enfoques más influyentes en la epistemología de las ciencias sociales.

El proyecto teórico de Gergen se inicia como un intento de sistematizar una "psicología social posmoderna", que proponga una teoría del conocimiento crítica de los fundamentos racionalistas y empíricos en los cuáles se forjaron las ciencias sociales desde sus inicios. Gergen distingue dos tradiciones clásicas que determinaron las formas de entender la naturaleza del conocimiento en el siglo XX. Mediante su propuesta, Gergen intentará desafiar ambas tradiciones. 
Por una parte, Gergen indica que la "tradición exógena" adopta una posición dualista que asume la existencia de una realidad externa objetiva contrastando con la existencia de una realidad mental privada y subjetiva. El conocimiento de la realidad es válido cuando las representaciones mentales internas del sujeto se ajustan adecuadamente a los estados objetivos de las cosas en el mundo exterior; en palabras de Rorty, cuando la mente es "el espejo de la naturaleza". Esta tradición enfatiza las condiciones externas a la mente humana en la relación sujeto-objeto que constituyen el conocimiento. Gergen indica que la 'tradición endógena' -con fuerte influencia Kantiana- propone que el conocimiento está determinado por la existencia a-priori de condiciones mentales que constituyen el objeto conocido. Si bien esta tradición también asume un dualismo epistemológico, el conocimiento según sugiere Kant es una proyección de las estructuras internas previas a la experiencia. El foco en esta tradición está puesto en el mundo privado y subjetivo del sujeto que conoce.

Gergen indica que ambas tradiciones han fallado en ofrecer una visión suficientemente plausible sobre la naturaleza social del autoconocimiento y del conocimiento de la realidad. El autor insiste en que tales tradiciones han desestimado el valor determinante que poseen el ámbito de lo social en la determinación del conocimiento. Éste será el punto de partida de la crítica sistemática de Gergen a la modernidad.

El proyecto crítico del autor estará fundamentado en diversos elementos de la sociología del conocimiento de Latour y Woolgar, y en el trabajo de Feyerabend, Kuhn y Laudan. Además, la propuesta de Gergen se nutre de la teoría de las representaciones sociales de Moscovici, del análisis del discurso (Potter y Wheterell), de la psicología dialógica de Hermans y de la psicología social crítica de Sampson y de Buss.

Sin embargo, y tal como el propio Gergen lo reconoce, es el trabajo de Berger y Luckmann el que presenta la influencia más importante en su trabajo. Estos autores indican que nuestra realidad cotidiana es socialmente construida mediante la objetivización de patrones sociales que son construidos y negociados en el seno de nuestras prácticas sociales diarias. El principal medio de objetivización de estos patrones serán las operaciones lingüísticas cotidianas que se dan en cada comunidad social. Por lo tanto, la realidad es construida como un proceso histórico dentro de las interacciones sociales permitidas por el lenguaje. Berger y Luckmann indican que el lenguaje es el principal medio por el cual los humanos acumulan y comunican el conocimiento que ellos han construido de generación en generación. Esta acumulación y traspaso de información mediante las continuas interacciones sociales en el lenguaje construyen y reproducen la realidad. Así, para Berger y Luckmann los humanos crearían y reproducirían una realidad social compartida, la cual existe solamente como un producto de la actividad social humana.

A continuación, detallaremos algunas de las principales premisas del construccionismo social.

\subsection{Realidad y conocimiento en el construccionismo social}

Como ya hemos indicado, Gergen toma las ideas de Berger y Luckman como base para indicar que la realidad y el sujeto son construcciones sociales, y que la pretensión del conocimiento objetivo sobre estos es un lastre que proviene de la tradición racionalista que fundó las ciencias sociales. Este supuesto conocimiento objetivo no es, pues, más que una pura ilusión (7). Sin embargo, como Hacking indica acerca de las propuestas de Berger y Luckmann: "They did not claim that nothing can exist unless it is socially constructed" (1999:25). De esta forma, Gergen comienza a distanciarse de sus influencias mediante la radicalización de sus postulados.

En términos generales, Gergen propone una teoría del conocimiento relativista que pone el énfasis de su análisis en las formas en que las personas explican la realidad y a ellos mismos. 


\section{(i) "There are no transcendentally privileged accounts of what we take to exist" (Gergen 1997:33)}

Para Gergen no existe ninguna explicación de la realidad que sea más plausible que otra. Con una fuerte influencia de Kuhn, Gergen indica que toda verdad adquiere su validez en el marco de la comunidad que la construye y la legitima como tal. Además, con una clara influencia de la filosofía de Rorty, Gergen indica que todo entendimiento de la realidad se construye, negocia y renegocia en el lenguaje, como un juego discursivo. Gergen indica lo siguiente: "there is no foundational description to be made about an 'out there' as opposed to an 'in here', [...] once we attempt to articulate 'what there is' we enter the world of discourse" (1997:72).

Para Gergen, el conocimiento es una expresión de la estructura social y de los significados sociales que la comunidad enuncia y acepta como tal. Lo que nosotros llamados conocimiento, no es un asunto sobre hechos de un mundo externo y objetivo, sino que es la pretensión hegemónica de un grupo social que intenta ilegítimamente proclamar la superioridad de su forma de entender la realidad por sobre otra. Para el construccionismo social todo aquello que referimos del mundo no está determinado por tal así denominado "mundo" sino, más bien, ya está socialmente determinado $y$, por lo demás, está socialmente determinado de acuerdo al grado de nuestro compromiso previo con una específica comunidad social.

Como consecuencia de lo señalado, Gergen indica acerca del socio construccionismo lo siguiente: "Remove the privilege of any person or group to claim superior knowledge of what there is. With respect to truth (a match of word and world) or reason (the arrangement of words themselves), no science, religion, philosophy, political party or other group can claim ultimate superiority" (1997:36).

\section{(ii) “Whatever account we give of world or self finds its origins within relationships" (Gergen 1997:34)}

Complementando lo indicado en el punto anterior, Gergen indica lo siguiente: "Language gains its capacity for meaning from relationships - from the way in which it is used as people coordinate themselves with each other and the world about them" (1997:36).

Para Gergen, los juegos del lenguaje en los cuales emergen las verdades compartidas por una comunidad tienen un valor funcional, es decir, coordinar a los diferentes sujetos en torno a visiones construidas sobre la realidad. En este sentido, Gergen indica que en el construccionismo social: "la verdad parece ser una cuestión de perspectivas, y éstas productos de intercambios y consensos sociales, es decir, construidas en los sistemas de comunicación social” (1997:20). El conocimiento en esta perspectiva es comprendido como relacional, en tanto mantiene a las comunidades cohesionadas y se crea y re-negocia dentro de ellas mismas. Como señalan Ibañez, la veracidad de cualquier enunciado sobre la realidad solo es determinado por el nivel de argumentación y la posición en la red conversacional que tenga quien lo enuncia, siendo un consenso derivado de una interacción social.

En el construccionismo social, la realidad es, a fin de cuentas, un conjunto de significados conversacionales que son socialmente compartidos.

(iii) Language primarily functions as social action, constitutive of one or more traditions (Gergen 1997:34)

Tal como hemos indicado, la pretensión de un conocimiento objetivo es el mero resabio de una de las tantas tradiciones que intentó definir la realidad durante el siglo XX. Por lo tanto, la objetividad es imposible, en tanto todo conocimiento es relativo a la comunidad al cual pertenece. 
Para Gergen, participar en el lenguaje y en la construcción de la realidad que éste propone es participar en una forma de vida o en una tradición específica que reproduce un entendimiento específico de la realidad. Luego, el lenguaje actúa como una proyección de las creencias y representaciones que una comunidad específica comparte. Participar en el lenguaje, es participar en la construcción y reproducción de ciertas representaciones que una comunidad posee.

Este último punto de crucial en el desarrollo de las ideas relativistas de Gergen. Las formas que tenemos de referirnos y de conceptualizar la realidad no reflejan una realidad externa, sino que nuestra participación en ciertas comunidades de significado. Por lo tanto, el conocimiento no solo es relacional, sino que también es visto como un proceso histórico.

Hasta este punto, podemos darnos cuenta que en el construccionismo social, el conocimiento de la realidad no es el producto objetivo de hipótesis comprobadas, dado que las categorías utilizadas en estos procesos ya reproducen una cierta forma de entender el mundo. Aquello que tomamos por "realidad" es el mero producto de negociaciones sociales.

Cualquier sentencia $S$ sobre el mundo es creada dentro de una comunidad social específica. $S$ tiene sentido solo dentro de la comunidad en la cual ha sido enunciada, por lo tanto, la validez de $\mathrm{S}$ depende de las categorías sociales que la sostienen como tal. De esta manera, las diversas formas que las distintas comunidades tienen de definir la realidad son para Gergen meras formas de conversación.

Con todo lo que hemos señalado, podemos indicar que el construccionismo social:

S: 'Existe un mundo independiente de nosotros' no refiere al término 'mundo', sino que S constituye una proyección de las creencias y representaciones de una comunidad C.

Por lo tanto:

S es una verdad relativa a las creencias y representaciones de C.

\subsection{El status del sujeto en el construccionismo social}

Siguiendo los supuestos epistemológicos antes descritos, Gergen indica que: "Language is a system unto itself, a cultural form that owes its existence to a collectivity of participants. Its structure pre-exists any single individual, and if sense is to be made, the individual must essentially participate in the communal conventions. [Individuals] gain their status as selves by taking a position within a pre-existing pronoun in a culturally shared linguistic system. [...] people do not speak their experience; rather, without forms of speaking they could not claim to have an experience" (1991:110).

En el construccionismo social el sujeto es, precisamente, una construcción social. La expresión "yo" no solo denota la enunciación de una forma de conciencia (autoconciencia), sino que es la misma palabra "yo" como entidad lingüística pre-existente la que permite la existencia de un "yo" consciente. De esta forma, la enunciación de la propia existencia consciente es permitida solo por los términos socialmente construidos que empleamos para realizar tal acción. Luego, el sujeto no es nada más que el engranaje de operaciones lingüísticas en las cuales se desenvuelve, es decir, el sujeto es una "construcción conversacional". En consecuencia, la persona identifica un sentido compartido de sí mismo solamente en las formas conversacionales en las que participa, surgiendo esta identificación desde los roles sociales que uno desempeña en ciertos contextos. Por ejemplo, ser "estudiante", ser 
"profesor", ser "padre", entre muchos otros. Para el construccionismo social, el sujeto es la mera ejecución de un rol permitido los términos lingüísticos previos que la sustentan.

Sobre esto, Bravo indica lo siguiente: "El yo será entendido para los construccionistas como una narración que se hace inteligible en el seno de las relaciones vigentes, a saber, un relato de relatos en tanto el sustrato del yo esté situado a partir de relatos de familiares, en los relatos de cuentos de hadas en la infancia, los relatos populares, el relato cotidiano de los sucesos de una mañana cualquiera, los relatos con un amigo, etc." (2002:3).

Siguiendo esta conceptualización, Gergen indica que el sujeto es un pastiche de significaciones, relatos, discursos y significaciones externas. Poco a poco, y como producto de la ejecución de diversos roles en diversos contextos sociales, el self es colonizado por los significados externos provenientes de esta multiplicidad contextual. Así, Gergen señala que cuando el sujeto no soporta el superávit de información que proviene de esta multiplicidad contextual, el self se satura (saturated self), lo que en definitiva lo fragmenta (fragmented self) para pasar a ser finalmente vaciado (empty self).

Gergen afirma lo siguiente: "Social saturation furnishes us with a multiplicity of incoherent and unrelated languages of the self. [...] This fragmentation of self conceptions corresponds to a multiplicity of incoherent and disconnected relationships. The fully saturated self becomes no self at all" (1991:6-7).

En el construccionismo social el sujeto se diluye en medio de la multiplicidad conversacional, se escinde para dejar de existir entre sus múltiples investiduras conversacionales y permanecer como un mero entrecruzamiento de narrativas foráneas. Esto ha sido denominado por el autor "sujeto multifrénico", lo cual refiere a la característica principal del sujeto posmoderno.

Finalmente, en el construccionismo social la inteligibilidad del sujeto ( $s e l f$ ) depende del grado en que los otros participantes en la trama conversaciones confirman y legitiman el rol que el self contextual toma en la red conversacional. De esta forma, el sujeto es una negociación constante e inestable, que lo hace vivir en una condición de constante interdependencia precaria.

Gergen afirma lo siguiente: "Este depender de los demás sitúa al actor en una posición de interdependencia precaria. Ya que del mismo modo que la autointeligibilidad depende de si los demás están de acuerdo sobre su propio lugar en el relato, también la propia identidad de los demás depende de la afirmación que de ellos haga el actor. El que un actor logre sostener una autonarración dada depende fundamentalmente de la voluntad de los demás de seguir interpretando determinados pasados en relación con él” (1996:183).

\section{El construccionismo social y algunos de sus dilemas}

En la siguiente sección se exponen algunos puntos problemáticos del construccionismo social, en referencia a lo siguiente: (a) la plausibilidad de los postulados epistemológicos y (b) las consecuencias que tienen los postulados construccionistas en la praxis de las ciencias sociales.

\subsection{El problema de las condiciones de verdad y la regresión al infinito}

En el construccionismo social cualquier sentencia $S$ sobre la realidad refiere a las representaciones y creencias que una comunidad específica posee sobre aquello que la "realidad es", no a la realidad "en sí misma", algo que por lo demás no existe para Gergen. De este modo, cualquier enunciado acerca de la realidad no representa una forma de relación con una entidad que es previa a la enunciación hecha de ésta -aunque esto ya suena poco plausible-, sino 
que la constituye en el acto mismo de enunciación. Gergen lo explica del siguiente modo: "Each discourse grows from a community of language users, and each constructs what we take to be a singular object in a different way. In this sense it is through relationships that our worlds are created, through which all that we take to be beautiful, valuable, and worthy of commitment are constituted. And it is through relationships that we may, at any time, begin the process of reconstructing the world" (1997:4).

Se puede observar que toda sentencia $S$ es verdadera solamente dentro de una comunidad conversacional en la cual S es expresada. Por ejemplo, la sentencia F: "todo puede ser explicado en términos físicos" es verdadera solo dentro de la comunidad que comparte ese acuerdo social sobre la forma de entender la realidad, a saber, la comunidad científica (C). Luego, para el construccionismo social, S solo puede ser verdadera dentro de $\mathrm{C}$, dado que $\mathrm{S}$ es expresión de las representaciones y creencias de $\mathrm{C}$.

Es importante señalar en este punto que Gergen propone un escepticismo relativista respecto del concepto de la verdad, es decir, no podemos conocer la verdad objetiva (digamos "verdad en todos los mundos posibles") sino que solamente verdades relativas y contexto-dependientes. Luego, para Gergen, cualquier intento por entender la veracidad de un enunciado fuera de la comunidad en la cual éste es construido no tiene sentido, dado que la veracidad de un enunciado es siempre relativa a tal comunidad. Sin embargo, es esta noción de la verdad la que se torna problemática incluso dentro de la misma propuesta socioconstruccionista.

Gergen no parece negar la existencia de algunas "verdades"; sin embargo, para el autor todas éstas son verdades relativas a específicas comunidades, luego, no objetivas. Esto se torna problemático si preguntamos por las condiciones de verdad de un enunciado específico dentro de una comunidad específica, a saber, qué es lo que hace cierto a S en C (es importante señalar que no estamos analizando una aproximación relativa a la verdad desde un punto de vista no relativo, sino que estamos intentando analizar como tales 'verdades relativas' logran justificar el estado de 'verdad' relativo a tal comunidad, una pregunta completamente justa dado el concepto de verdad que presenta el autor), o en otras palabras, que es lo que hace verdadero un enunciado lingüístico dentro de la comunidad en la cual este enunciado es realizado, pregunta que Gergen no parece negar.

Siguiendo los postulados de Gergen, ante la pregunta el autor necesitaría decir que aquello que hace verdadero diremos- una sentencia S en la comunidad C es W*: "la creencia -basada en un acuerdo social- que C tiene sobre la veracidad de $\mathrm{S}^{\prime}$. Sin embargo, después de ofrecer esta respuesta, podríamos preguntar por las condiciones de verdad de $\mathrm{W}^{*}$, preguntando ¿qué hace verdadero a $\mathrm{W}^{*}$ en $\mathrm{C}$ ? Siguiendo la forma de razonar del construccionismo social, la respuesta a esta preguntara tendría que ser algo como $\mathrm{W}^{* *}$ : "la creencia que $\mathrm{C}$ tiene en la creencia que $\mathrm{S}$ tiene sobre la veracidad de $C^{\prime \prime}, \mathrm{y}$ así ad infinitum ( $\mathrm{W}^{* * *}, \mathrm{~W}^{* * * *}$, etc.).

Tal como podemos observar, el construccionismo social remite al infinito al momento de especificar las condiciones de verdad de los enunciados "relativos" a la comunidad en los cuales son realizados. Esto sin duda reduce la plausibilidad de la teoría en tanto una regresión al infinito no logra explicar de ninguna forma lo que intenta explicar.

\subsection{Construccionismo social y realidad física}

Es bastante justo señalar que no todas las teorías que proponen que algunos aspectos de nuestra realidad son construidos caen en un relativismo ontológico absoluto, y en sus consecuentes problemas. Es más, se puede decir que muchos de los elementos entre los cuales la existencia humana se despliega son de hecho "construidos" en comunidad, y por lo tanto, la existencia de comunidades sociales es condición necesaria para la existencia de tales 
elementos. Sin embargo, del hecho de reconocer que algunos elementos de nuestra existencia son construidos socialmente al hecho de reconocer que toda la realidad es una construcción relativa a ciertas comunidades existe un gran salto lógico. Por ejemplo, John Searle reconoce dos tipos de eventos: (a) eventos humano-dependientes (human-dependent facts) y (b) eventos humano-independientes (human-independet facts) (8). En esta propuesta, eventos como el "matrimonio" o el uso del "dinero" son contratos sociales que han sido construidos y que solo tienen sentido dentro de comunidades humanas específicas; dependen de la existencia de una comunidad que acuerda su veracidad y su uso. Sin embargo, la realidad física, las estructuras químicas y las condiciones biológicas, por ejemplo, no parecen depender del ser humano para existir. Así, para Searle, nuestra realidad es el producto de la interacción entre estos dos tipos de eventos, presentando una plausible propuesta que entrecruza elementos de diferente naturaleza ontológica sin caer en el relativismo absoluto. Aunque no comparto todo el proyecto de Searle, su distinción propone al menos un elemento bastante útil en la filosofía de las ciencias sociales. Sin embargo, no es el caso del socioconstruccionismo.

Tal como señala Nightingale y Cromby, el construccionismo social de Gergen frecuentemente ha negado el cargo de ser una forma radical de escepticismo o antirrealismo, pero a su vez, no ha ofrecido una defensa plausible para tales cargos (9). Sobre esto, Gergen declara: "For the constructionist there are no problems, causes, forces, structures and so on that does not derive their status as such from communally based interpretations. This is not to propose that 'nothing exists' or that 'we can never know reality' -common misunderstandings of constructionism[...] constructionism serves as a continuous reminder of Gregory Bateson's dictum, 'the map is not the territory' " (2001:100).

Como ya he señalado en otras ocasiones (López 2010), si Gergen insiste en que la construcción de la realidad solo es realizada por medio de operaciones lingüísticas, y que no hay nada fuera del lenguaje, el antirrealismo del socioconstruccionismo no es un mero "malentendido", ni menos una "mala interpretación", dado que, aunque el autor intente argumentar lo contrario, no podemos distinguir finalmente el mapa (los discursos), del territorio (la realidad); es más, acá no existen discursos "sobre" la realidad, ya que éstos "son", finalmente, la realidad.

El antirrealismo de Gergen se sugiere muy claramente en textos como el siguiente: "People do not speak their experience; rather, without forms of speaking they could not claim to have an experience" (1991:110).

Así, Gergen parece confundir dos elementos diferentes, a saber, la experiencia de X con la enunciación de la experiencia de $X$, donde al parecer, la enunciación es condición de los enunciados. Exploremos ahora algunos de los problemas derivados de tales planteamientos.

\subsubsection{El problema de la realidad física}

Tal como hemos sugerido, Gergen reduce todo enunciado sobre la realidad a negociaciones generadas en el seno de comunidades conversacionales específicas. Sin embargo, ¿qué sucede con los enunciados respecto de la realidad física? Según Gergen, éstos tienen su origen en comunidades humanas, luego tales comunidades son condición necesaria para la realidad, ¿qué quiere decir esto? Boghossian, refiriéndose a este punto, indica lo siguiente: "Many facts about it [the reality] obtained before we did. How then could we have constructed them? For example, according to our best theory of the world, there were mountains on earth well before there were humans. How, then, could we be said to have constructed the fact that there are mountains on earth?" (2006:26).

El construccionismo social parece tener como consecuencia una idea bastante extraña acerca de la realidad física, a saber, que nosotros creamos algo previo a nosotros por medio de nuestras operaciones lingüísticas. Por ejemplo, 
desde el punto de vista construccionista, la historia de nuestro planeta es solo otra conversación que toma lugar en una comunidad específica, en consecuencia, la física, la geología, biología evolutiva, etc. y todos sus conocimientos derivados serían "formas de conversación" que no poseen ningún grado de objetividad por sobre otras. Por ejemplo, el término "protón" o "partículas subatómicas" no refieren en absoluto a la existencia de entidades con existencia objetiva, sino que a construcciones socio-históricas (Gergen presenta este argumento respecto de varios temas, entre ellos, el "instinto materno" y otras "formas de conversación"). Tales términos dependen de la comunidad en las cuales son enunciados, a saber, la comunidad científica. Luego, la rareza de las ideas construccionistas deviene más clara: ¿cómo es posible que los protones dependan de las conversaciones, pero a su vez las conversaciones dependan de los protones para ser performadas? ¿Cómo es que el status ontológico del conocimiento de una montaña que tiene 50 millones de años dependa de una especie que es posterior? Sin duda, esto es muy difícil de aceptar.

\subsubsection{El problema experiencial}

El construccionismo de Gergen sugiere que sin las formas del lenguaje no podríamos ni siquiera decir que hemos experimentado algo. En este sentido, las diversas formas lingüísticas son condición necesaria para tener una experiencia y conocimiento de nuestras experiencias. Este punto -aparte de ser una negación de todo el universo de la experiencia implícita o pre-reflexiva reconocida en el trabajo de Scheler, Husserl, Heidegger y Sartre y también reconocida en la neurociencias por Damasio, entre otros- contrasta con dos simples ejemplos: infantes humanos y personas sordo-mudos. En ambos casos, hay personas que no son capaces de enunciar verbalmente ninguna expresión, los bebés porque aún no desarrollan el lenguaje y los sordo-mudos porque carecen de tal capacidad. En ambos casos ellos no pueden hablar ni participar en conversaciones por medio de 'enunciados lingüísticos', luego ¿cómo puede Gergen explicar que tales personas tienen conocimiento del mundo físico sin siquiera participar en las conversaciones de las cuáles éste dependería? Indudablemente, nuestro conocimiento y experiencia del mundo es más que conversaciones, pero Gergen no provee una explicación plausible acerca de esto.

Hasta este punto, necesitamos indicar que algunos de los principales méritos que se le atribuyen al construccionista social son, entre otros: (a) Trasladar el foco del estudio del conocimiento a la relación entre los significados sociales, con esto, ofrecer igualdad y tolerancia entre las diversas formas de conocimiento; (b) Tomar conciencia de las consecuencia que el saber tiene en la esfera práctica de los social; (c) Integrar a la cultura como condición necesaria en el proceso de construcción de conocimiento.

Sin embargo, así cómo podemos advertir tales puntos en la literatura construccionista, también podemos advertir que el antiesencialismo propuesto por el construccionismo social, no solo se fundamenta en argumentos poco claros, sino que se torna cuestionable cuando analizamos las consecuencias prácticas que enfrenta. Luego, tras este manto de tolerancia teórica y relativismo epistemológico que propone el construccionismo, se pueden advertir ciertos problemas prácticos, que se extienden en medio de la misma falta de claridad de sus argumentos fundamentales. Analicemos las consecuencias que tal teoría tiene en su praxis.

\subsection{El problema de la valoración y la significación de lo 'social' y el 'locus of meaning'}

Tal como hemos podido advertir, en el construccionismo social el conocimiento es una construcción social negociada y actualizada en las redes conversacionales. Luego, en medio de la multiplicidad de conversaciones a las cuáles hace referencia el sujeto, éste no tiene otra opción que diluirse y "dejar de existir". Así, en el socioconstruccionismo no existe motor interno ni significación individual de la voluntad, todo acto y decisión está socialmente determinada. 
En vista de lo anterior e incluyendo el supuesto de la interdependencia precaria, el locus of meaning, esto es, el lugar donde ocurre y se actualiza el significado personal del Yo y de la realidad, está en las redes conversacionales. Pues bien, creemos que derivado de este supuesto, en el socioconstruccionismo surgen los siguientes problemas:

4.3.1. En el construccionismo social el sujeto es básicamente un sujeto-narrador, sin embargo la teoría no parece explicar que el sujeto "comprenda lo que se narra", entendiendo, que desde las ideas construccionistas, al menos debe existir un ente "que narre" o que "converse", para que en tales actos se negocien los significados sociales. De no existir siquiera esto, pues bien, la teoría se torna contradictoria.

Supongamos que tal como sugiere Gergen, el sujeto deja de existir abrumado por las significaciones externas producto de la "saturación social". Pues bien, si realmente yo no soy el que significa lo que narro (porque la sociedad lo hace y no existo sino en conversaciones externas), tal parece que, entonces, debiera existir alguna especie de entelequia encargada de entender por mí y, en consecuencia, hablo de lo que no entiendo tal como si yo fuera una terminal computacional o un autómata. Luego, la externalización del significado implica consecuentemente la inexistencia de comprensión simbólica por parte del Yo; ontológicamente el sujeto es constituido como un autómata pues no hay un "yo" que signifique nada. Si describimos a un sujeto que se significa completamente en las conversaciones, se niega, por ejemplo, cualquier posibilidad de acto libre y de significación de la voluntad. No existe, en consecuencia, libertad para elegir las palabras con las cuales me refiero a mí mismo y al mundo. Sin embargo, la hipótesis de una voluntad completamente determinada por el contexto, parece distar de la evidencia cotidiana, en la que un sujeto finalmente puede decidir no cumplir el rol que le impone la sociedad.

Siguiendo en esta línea, si pensamos aún más prácticamente este asunto, toda "revolución social", elemento de continuo estudio desde estas corrientes, está determinada socialmente, lo que deviene en tautología. Si no hubiera libertad y el locus of meaning es completamente externo, ¿cómo se pueden consensuar significados sociales, si no hay un "yo" que signifique? ¿Cómo se negocian o quién negocia el conocimiento? Este argumento parece provocar algunas dificultades cuando se le intenta contrastar con el mundo de lo cotidiano.

4.3.2. En segundo lugar, tal parece ser que los demás comparten el mismo problema que yo. Si el locus of meaning es externo y no hay espacio interior para significar nada, ninguno de los que me habla entendería lo que habla, porque todo meaning está en un "entre" ellos y yo. Los demás, como yo, no tienen libertad ni voluntad, todo acto es producto del contexto conversacional que me "construye". Por ejemplo, nuevamente, conceptos como el de libertad y voluntad no tiene cabida en este enfoque en ninguna de sus expresiones.

\subsection{El problema de la responsabilidad personal}

El argumento señalado en el punto anterior, nos invita a reflexionar otras implicancias a cuales deberíamos prestar atención. Tomemos nuevamente los conceptos de voluntad y libertad someramente enunciados en el apartado anterior, para que nos sirvan de ejemplo claro en lo que queremos señalar.

Si yo no significo lo que narro, es decir, no lo entiendo por mis propios términos, como consecuencia, yo no soy responsable de los actos que se siguen de mis deliberaciones. Cualquier voluntad personal no será, entonces, libre, es decir responsable sino socialmente determinada. Lo que deviene en graves consecuencias en el nivel práctico. Si hay un Yo que tiene un locus of meaning completamente externalizado, sin libertad de someter a juicio subjetivos sus actos, el Yo no puede responsabilizarse de nada, lo cual, conlleva importantes implicancias a niveles prácticos que el construccionismo no puede explicar. Así, el socioconstruccionismo no solo negaría la posibilidad de la libertad, sino que con esto, una facultad derivada de esta, la responsabilidad. 
Observemos pues, un ejemplo típico en la penalización criminal:

(a) Un sujeto $X$ asesina a un sujeto $Y$.

(b) X emerge en el seno de las redes conversacionales.

Siguiendo las ideas del construccionismo, podríamos decir que en (a) no hay ninguna responsabilidad de $X$, ya que $X$ no es libre de someter a juicio sus deliberaciones; $X$ no tiene voluntad libre, porque, precisamente, toda su significación es externa, esto es (b). Luego, si hay un sujeto que deja de existir y se diluye, esto es, (b), no hay nadie que se responsabilice de sus actos: (a), dado que un sujeto, es sujeto solo dependiendo del contexto, en tanto (b). Imaginemos pues ahora, las consecuencias de tal planteamiento en temas relativos al crimen en todas sus formas.

Es comprensible que alguien se queje de que exageramos. Sin embargo, es exactamente lo que se sigue. A su vez, otro lector podría indicar: "a pesar de eso, existen parámetros y pautas sociales que indicarían que está bien y que no, lo que nos daría la posibilidad de enjuiciar el acto". Pues bien, respondamos que, entonces, no sólo X no sabría lo que está haciendo, sino que tampoco aquellos que enjuicien el comportamiento de $\mathrm{X}$, pues ellos tampoco podrían significar como buenos o malos tales actos. En segundo lugar, supongamos que la inocencia de (a) dependa del modo de argumentar; pues bien, todavía nos encontraríamos con el problema de que no existirían jueces capaces de juzgar acerca de tal argumento, en consecuencia, ya se ve que el mismo acto de argumentar deviene inútil. En síntesis, ¿quién "argumenta" si el yo no puede significarse lo que narra, o si en último lugar el yo desaparece en medio del superávit de información?

Las condenas y premios los debiera recibir "el sistema" quien es quien significa o quien "conversa". En otras palabras, desde el socioconstruccionismo el "contexto" en el que ocurre (a) fundamenta (b) los culpables de (a). Sin embargo, ¿se puede culpar al contexto? ¿Cómo aplicamos la justicia al contexto? La justicia tendría que acomodarse al contexto, pero ¿es esto finalmente, justicia?, ¿no se convierte esto en el origen de la legitimización de la conducta irresponsable si ésta consta con una buena argumentación a posteriori? El recurso de la coresponsabilidad tampoco resuelve el problema, porque para que haya co-responsabilidad se requieren, precisamente, dos entes -el contexto y el sujeto-, pero ya vemos que Gergen declara vacío al self, con lo que sólo nos queda hacernos la obvia pregunta si acaso el contexto no son los otros y si, en consecuencia, ellos no pueden al igual que el self disfrutar del privilegio de eludir su responsabilidad vaciándose y desvaneciéndose.

Finalmente, la idea misma del locus externalizado se opone a todas capacidades humanas que fundamentan los conceptos anteriormente señalados, luego, reduce toda conducta humana a la mera reproducción autómata de significaciones y voluntades foráneas sin poder tomar decisión respecto de ningún tipo de culpabilización, penalización o cualquier acto que implique capacidad volitiva.

\subsection{Sujeto, significación personal y rol}

Si en el construccionismo social el locus of meaning es externo, debemos preguntamos lo siguiente: ¿cómo significan los sujetos los roles ejercidos y que son entregados por la sociedad? En el socioconstruccionismo, el sujeto encuentra su identidad en la realización del rol específico (estudiante, profesor, mujer, hombre, etc.). Así, toda identificación de un posible yo es fragmentada y cambiante, tal como los roles ejercidos en la sociedad (yo fragmentado), elemento fundamental del sujeto posmoderno según Gergen.

El construccionismo tendría dos opciones para abordar la pregunta señalada: (i) indicar que no hay significación del rol del sujeto, y que, por lo tanto, su ejercicio se realiza de forma automática e irreflexiva; (ii) que el rol significaría 
al sujeto. Sin embargo, ambas opciones se tornan problemáticas para el socioconstruccionismo. Por una parte, Gergen no logra explicar la libertad que cada uno posee de enjuiciar y demostrar conformidad o disconformidad con los roles ejecutados, sin que esto signifique, en consecuencia, dejar de ser uno mismo. Por otro lado, tampoco se explica que sea posible rechazar algunos roles.

Gergen omite explicar el modo en que se significan los roles sociales ejercidos. Tal parece que, entonces, el sujeto no llega a ser tal y, paradójicamente, queda convertido en aquello que Gergen rechazaba. Así, tal como lo señala Balbi, un planteamiento de esta naturaleza externalista, involucra una mente sin subjetividad, un mecanismo similar a un sujeto autómata determinado completamente desde lo social.

\subsection{Socioconstruccionismo y la imposibilidad de una ciencia social con "personas"}

Tal como hemos indicado en puntos anteriores, a pesar de que Gergen intenta negarlo, su propuesta deviene antirrealista. El problema para el construccionismo no surge cuando propone una realidad puramente 'construida', al menos una postura de esta naturaleza podría reconocer "grados de realidad de las construcciones" o reconocer que las "construcciones" pueden ser acerca de una "realidad epistemológicamente incognoscible"; el problema en este punto surge, fundamentalmente cuando se entrega el papel de tal construcción a los "discursos".

Tal como cualquier científico social podría reconocer, las ciencias sociales -al igual que todas las ciencias- proponen problemas a los cuáles dirigir su desarrollo, siendo estos problemas teóricos o prácticos. Luego, en el intento de responder a tales problemas las ciencias continúan su desarrollo. Sin embargo, un elemento distintivo en las ciencias sociales es que su teorización se alimenta y retroalimenta en la "praxis", y a su vez ésta se confronta continuamente con la teorización en una espiral metodológica interminable. En términos prácticos, en ciencias sociales, el acercamiento a las personas es un elemento fundamental. Por ejemplo, el término "opresión", se aborda en los oprimidos, la "pobreza" en los pobres, y así sucesivamente. Sin embargo, consideramos que los cambios propuestos por el construccionismo social -en cualquier forma de conceptualizar las ciencias sociales-, devienen en consecuencias prácticas que deben ser tomadas en cuenta a la hora de hacer ciencias sociales. Decimos esto porque las formas de comprender la realidad, el sujeto, el conocimiento, etc., no se articulan como mero ejercicio retórico, sino que, y finalmente, constituyen modos de acercamiento práctico a los sujetos (el pobre, al oprimido, etc.). De este modo, cuando revisamos estas maneras de acercamiento, podemos preguntarnos lo siguiente: ¿cómo es posible hablar de grupos sociales oprimidos, de gente que "sufre" pobreza y desigualdad, de gente que es "víctima de injusticia", si todo es una mera construcción lingüística, es decir, si no existen como tales sufrimientos ni injusticias? Esto se vuelve problemático una vez que empezamos a suponer que toda la realidad es construida, y, que el estatuto de realidad de un problema proviene de la calidad de su argumentación y posición en la "red conversacional". Pero, entonces, no existirían realmente la desigualdad ni la pobreza, y por lo tanto, sólo existen en tanto construcciones lingüísticas. Sin embargo, es muy diferente decir que desde la teoría podemos "comprender" una situación problemática, a decir que tal problema "solo existe como conversación".

El socioconstruccionismo parece olvidar que si bien podemos "construir" problemas desde las conversaciones contextuales, existe gente de carne y hueso, que muere de hambre, que sufre por la desigualdad, que es víctima de abusos, que es asesinada por un dictador, etc.; $Y$, a su vez, el socioconstruccionismo no parece ponderar que esta gente sirve como poderosa retroalimentación al trabajo de las ciencias sociales, aportando no solo elementos teóricos nuevos, "nuevos elementos conversacionales", sino que aportando aquello que ellos directamente pueden aportar, su experiencia, la cual es completamente negada por Gergen. 
Al parecer, para el construccionismo las personas son un elemento problemático. El socioconstruccionismo olvida a las personas desde las cuales nace la praxis en ciencias sociales, olvida al indígena oprimido en favor del concepto de "opresión", olvida al pobre, en favor del concepto de "pobreza", etc. Todos estos conceptos meramente "construidos". Estamos de acuerdo con Sandoval, quien indica que: "Claramente los criterios que existen en un determinado momento histórico son coyunturales a ese momento y a esas prácticas sociales que los constituyen, pero esos criterios no son arbitrarios, y por el contrario están constreñidos por una realidad que duele, hace sentir hambre y genera temor, por cierto a una experiencia concreta: alguien que sufre el dolor, que padece el hambre $y$ que esta temeroso, pero el estatus de realidad de ese dolor, de esa hambruna y de ese temor es indiscutible, y por lo tanto requiere fijar una posición no relativa sino a esas 'reales' condiciones simbólico/materiales de existencia" (2000:69).

Podemos consensuar sin problemas que las formas de referir la 'opresión', la 'desigualdad' o cualquier problema social se origina en una cultura, y desde símbolos culturalmente compartidos. Sin embargo, tales formas de referir a un fenómeno son contrastadas y enjuiciadas por una realidad que no se puede negar, por un sujeto que muere, por una comunidad que sufre, etc. Resuenan acá las palabras de Burr, quien se pregunta: “¿Cómo podemos decir, por ejemplo, que ciertos grupos están oprimidos, si estos grupos y su opresión son construcciones que no pueden ser consideradas más verdaderas que otras?" (1995:14). Esto nos lleva a pensar lo siguiente: ¿es viable pensar que el status de realidad de las teorizaciones que ofrecen las ciencias sociales dependen de la mera argumentación?, ¿qué ocurre si logro argumentar coherente, y lógicamente el genocidio, el asesinato, la pederastia? Tal vez alguien en este punto diría: "pero eso no podría suceder, porque tales cosas no son lógicas ni coherentes". Sin embargo, desde el relativismo del socioconstruccionista, la respuesta podría acercarse a algo como: "usted dice eso, porque está asumiendo la existencia de una moral a priori, y recuerde, que ello también es un consenso, una conversación entre muchas'.

Por otra parte, el presente argumento obtiene fuerza, incluso, desde dentro del movimiento posmoderno, el cual Gergen, curiosamente, parece compartir. Por ejemplo, Michel Foucault indica que el término "realidad" (al cual también se refiere Gergen continuamente en su status de construcción lingüística) no poseería sentido alguno al decir que solo existe como "discurso" o "conversación". Desde este punto de vista, la propuesta de Gergen se volvería inviable, dado que: "Un ejemplo muy simple [de que la realidad no es una mera conversación o relato] es que la explotación capitalista se realizó sin que su teoría hubiese sido jamás formulada directamente en un discurso" (Foucault 1978:162). Sin embargo, aunque no existiese tal discurso, la experiencia de los explotados parece ser innegable.

Hasta acá, es claro que el antirrealismo y el relativismo de las ideas socioconstruccionistas reducen todos los problemas de las ciencias sociales, y a éstas también a meros juegos retóricos. Sin embargo, lo preocupante es que lo mismo ocurre con la experiencia de quien sufre. De pronto, el discurso se torna todopoderoso y adquiere la facultad de definir o descalificar cualquier experiencia de la realidad. Esto genera consecuencias que el construccionismo social no ha sabido argumentar, dado que si bien nuestros conceptos para referirnos a un fenómeno pueden ser relativos a un contexto, de esto no se sigue que la 'realidad' de tales conceptos sea un mero invento cultural, ni menos que su falsedad obedezca a una mera falta de argumentación en el mundo conversacional.

Finalmente, hay que indicar que el teorizar en y desde las ciencias sociales es una cosa, y otra cosa muy diferente que Gergen parece olvidar y negar sistemáticamente, es la experiencia de las personas a las cuales referir tal teorización. Luego, la solución para el construccionismo parece ser el desligarse completamente de las personas, y 
así, autodefinirse como un mero ejercicio retórico, sin embargo, ya no podríamos hablar de ciencias sociales, ni tampoco podría seguir argumentando su intención de ser una psicología social posmoderna, ya que prescinde que aquello que es el origen de los problemas a los cuales se dirigiría y retroalimentaría tal disciplina. Así, sería una ciencia social sin personas, lo cual no parece plausible.

\section{Consideraciones finales}

Suena bastante implausible negar la interrelación entre conocimiento de la realidad y las condiciones sociales en el que éste se da. Parece existir un amplio consenso entre filósofos y teóricos que refiere a la complementariedad entre ambos elementos (10). Por otra parte, tampoco podemos negar que existe una amplia gama de hechos que son ontológicamente construidos socialmente, tales como el uso de dinero, el matrimonio, el sistema económico, etc. Todos éstos tienen a las comunidades humanas como condiciones de existencia. Sin embargo, en el momento que Gergen no hace ninguna distinción ontológica entre elementos humano y no-humanos dependientes, parece ser que las ideas construccionistas generan más problemas de los que intenta resolver.

Si bien, consideramos que el construccionismo social sugiere profundos e interesantes cambios en el campo de la epistemología de las ciencias sociales y un nuevo esfuerzo por una re-sistematización de las mismas, creemos a su vez que la propuesta se torna implausible, antirrealista y determinista. Todo esto, finalmente, genera objeciones que este enfoque no ha sido capaz de contraargumentar durante el tiempo. Creemos, por el contrario, que la exclusividad que el construccionismo pone en las operaciones lingüísticas en el proceso de conocimiento de la realidad producen comprensiones implausibles de la naturaleza de la experiencia humana, realidad física, y sobre todo, problemas de coherencia interna de la misma teoría. Por ejemplo, podemos observar que Gergen ignora completamente el mundo de la experiencia tácita y la invariabilidad de ciertos hechos de la realidad física que de una o de otra manera estarían relacionados en el proceso de conocimiento de la realidad. La negación de tales evidencias en su movimiento escéptico restan plausibilidad al enfoque y generan un entendimiento sesgado e incompleto de lo que el autor intenta explicar. Luego, esto termina socavando su propia propuesta.

Tal como sugieren Nightingale y Cromby: "Continuing to ignore or downplay embodiment and materiality may eventually create the conditions for the tide of knowledge and practice to simply sweep social constructionism away. The many psychologists who have recourse to notions of embodiment and materiality, both in their practice and in their everyday lives, are unlikely either to resign en masse or wholly transform their approach simply because constructionism refuses to believe in them. It seems far more likely that social constructionism will simply make itself irrelevant and trivial, and so waste the valuable gains it has made" (2002:14).

Finalmente, creemos que el socioconstruccionismo debiera al menos aceptar sugerencias tales como las provenientes de la filosofía de Searle con el fin de evitar regresiones al infinito, contradicciones internas, reduccionismos, malentendidos entre otras cosas. Por lo tanto, concluimos que la exclusión de distinciones filosóficas claras por parte del construccionismo social le resta plausibilidad al enfoque.

\section{Notas}

(1) Para una mejor descripción de esto, revisar G. Feixas y M. Villegas (Constructivismo y Psicoterapia).

(2) Revisar Owens, en Foster (La Posmodernidad).

(3) Revisar Eagleton (Las Ilusiones de la Posmodernidad).

(4) El presente artículo extrae algunos elementos de la ponencia titulada "El problema de la Libertad en la epistemología Constructivista", presentada en el Congreso Internacional sobre Filosofía Cristiana y Libertad, 
organizado por la International Academy of Philosophy of Liechteinstein-PUC, en Octubre del año 2010, Santiago, Chile.

(5) Revisar M. Matthews (Appraising Constructivism in Science and Mathematics) y Cubero (Perspectivas constructivistas: La intersección entre significado, la interacción y el discurso).

(6) Para una descripción más detallada de tales fases y para una revisión de sus supuestos teóricos, revisar Neimeyer y Mahoney (Constructivismo en Psicoterapia), Feixas y Villegas (Constructivismo y Psicoterapia) y Feixas (Una Perspectiva Constructivista de la Cognición).

(7) Esta idea se puede apreciar claramente en Gergen (El Yo Saturado), caps. 1 y 2.

(8) Revisar Searle (The Construction of Social Reality).

(9) Revisar D. Nightingale y J. Cromby (Social Constructionist Psychology: a critical analysis of theory and practice).

(10) Para un exhaustivo análisis de esta relación, revisar Hacking (The Social Construction of What?)

\section{Bibliografía}

Boghossian, P. 2006. Fear of knowledge: against relativism and constructionism. Oxford: Oxford University Press.

Bravo, C. 2002. Hacia una comprensión del construccionismo social de Kenneth Gergen. Santiago de Chile: Universidad Bolivariana.

Burr, V. 1995. An introduction to social constructionism. London: Routledge.

Feixas, G. y Villegas, M. 2000. Constructivismo y psicoterapia. Bilbao: Desclée de Brouwer.

Foucault, M. 1978. La verdad y las formas jurídicas. Barcelona: Editorial Gedisa.

Gergen, K. (Ed.) 2001. Social construction in context. London: Sage.

Gergen, K. 1997. Toward a cultural constructionist psychology. Theory and Psychology 7: 31-36.

Gergen, K. 1996. Realidades y relaciones. Aproximaciones a la construcción social. Barcelona: Paidós.

Gergen, K. 1991. The saturated self: dilemmas of identity in contemporary life. Boston: Basic Books.

Gergen, K., 1985. The social constructionist movement in modern psychology. American Psychologist 40(3): 266275.

Hacking, I. 1999. The social construction of what? Cambridge, Mass.: Harvard University Press.

López, P. 2010. Discusiones acerca de la identidad personal ¿Fenómeno experimentado o construcción conversacional? Tesis para optar al grado de licenciado en Psicología y al título profesional de psicólogo. Viña del Mar: Pontificia Universidad Católica de Valparaíso.

Nightingale D. y Cromby, J. (eds) 2002. Social constructionist psychology: a critical analysis of theory and practice. Buckingham: Open University Press

Sandoval, J. 2000. Realidad, relativismo y pluralismo: o sobre cómo pensar una crítica al socioconstruccionismo sin ser positivista en el intento. Revista de Psicología de la Universidad de Valparaíso 1(1): 61-71.

Recibido el 24 Oct 2012

Aceptado el 15 Ene 2013 